BLS 32, No 1 2006. DOI: http://dx.doi.org/10.3765/bls.v32i1.3449 (published by the Berkeley Linguistics Society and the Linguistic Society of America)

\title{
A Closer Look at Salish Intransitive/Transitive Alternations ${ }^{1}$
}

\author{
DONNA B. GERDTS and THOMAS E. HUKARI \\ Simon Fraser University and University of Victoria
}

\section{Introduction}

Salish languages are noted for their "inchoative/causative" alternation: the inchoative forms are usually unmarked, while the corresponding causative verbs require the transitive suffix. This is demonstrated by the following Halkomelem data: '́a? 'get added' in (1) contrasts with qa?-t 'add it, put it in with' in (2): ${ }^{2}$

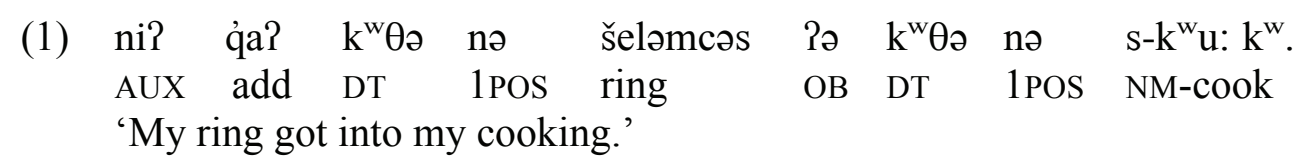

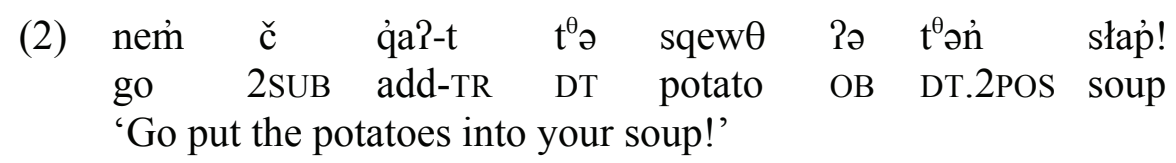

Such examples seem to be a prima facie case for deriving the causative verb from its intransitive counterpart (à la Levin \& Rappaport Hovav 1995). Indeed, Salish languages are "transitivizing" languages in the sense of Nichols et al. (2004), who looked at 18 intransitive/transitive pairs in 80 languages, including the neighboring Salish language Squamish, and rated them on the basis of whether the intransitive or the transitive alternant was morphologically marked. The verbs

\footnotetext{
${ }^{1}$ Halkomelem is a Central Salish language spoken by around one hundred elders in southwestern British Columbia. Data are based on fieldwork with Island Halkomelem speakers. We especially thank Ruby Peter and the late Arnold Guerin and Theresa Thorne for assistance with data. Thanks also to Sarah Kell and Kaoru Kiyosawa for research assistance, to Todd Peterson and Charles Ulrich for editing, and to SSHRC; Simon Fraser University; University of Victoria; Jacobs Fund; Phillips Fund; The Museum of Civilization, Ottawa; and the Canadian Consulate, Washington, D.C., for funding.

${ }^{2}$ The following abbreviations are used in glossing the data: APPL: applicative, ATTRIB: attributive, AUX: auxiliary, CNJ: conjunction, DT: determiner, EMPH: emphatic, FUT: future, LNK: linker, NM: nominalizer, OB: oblique, POS: possessive marker, Q: interrogative, SUB: subject, SSUB: subordinate subject, TR: transitive.
} 
Donna B. Gerdts and Thomas E. Hukari

in question all have bare root intransitive alternants and marked transitive alternants in Halkomelem. However, this result is somewhat misleading because, in fact, all syntactically transitive constructions in Salish, i.e., those with two direct nominal or pronominal arguments, take transitive marking. This has led some Salish scholars, for example, Kuipers (1968), Hess (1973), Jelinek (1994), and Suttles (2004), to the viewpoint that all verb roots in Salish languages are intransitive and require the addition of transitive morphology in order to serve as transitive stems. However, there is an alternative view taken by some Salish scholars, including Gerdts (1988a), Gerdts \& Hukari (1998), Nater (1984), and Thomason \& Everett (1993): the transitive suffix is a verbal inflection that appears on bases that are already semantically transitive. It is that viewpoint that we seek to explore in this paper.

First, we review some information regarding intransitive roots in Section 1. Then, we explore the issue of transitivity from three perspectives. Section 2 shows that around one hundred verb roots that appear with the transitive suffix do not occur as a $\varnothing$-form intransitive. Section 3 shows that around forty $\varnothing /$ transitive pairs show an unergative/transitive alternation, where the agent remains constant, rather than an inchoative/causative one, where the patient remains constant. Section 4 shows that many bare roots used unaccusatively seemed to be coerced into this frame by special semantics while the transitive alternants are more basic. We thus conclude that the Halkomelem data do not support the viewpoint that all roots are unaccusative or even that all roots are intransitive. Rather, Salish verb roots should be classified, like those in other languages, into intransitive and transitive roots.

\section{Intransitive Roots}

One way to explore the status of roots is to make a more complete survey of the $\varnothing /-t$ pairs in the language, classifying them according to the semantic properties of the base. A project that we have been undertaking for the last twenty years is testing Halkomelem verb roots in combination with the various suffixes. So far we have identified 489 verb roots and tested them in combination with twelve suffixes (transitive, causative, reflexive, desiderative, etc.). We checked with speakers to see if forms were acceptable and asked for illustrative sentences. We also took materials from our elicitations, texts, dictionaries, and composed a database coded for argument realization and semantic nuances. Our survey shows that the transitive suffix $-t$ can occur with 407 of the 489 roots in our sample $(83 \%){ }^{3}$

In oft-cited examples of the $\varnothing /-t$ alternations, such as those in Table 1 , the $\varnothing$ alternant is typically a state or process verb with an unaccusative frame. That is, the sole argument (syntactically, the subject) is semantically a patient/undergoer.

\footnotetext{
${ }^{3}$ The transitive suffixes are also used on bases that consist of more than a root. We have discussed the combinatorial properties of transitive suffixes elsewhere (see, especially, Gerdts 1988a) and limit the discussion here to cases where the suffix is attached directly to the root.
} 


\section{Salish Intransitive/Transitive Alternations}

Table 1. Examples of Transitive $-t$

\begin{tabular}{|c|c|c|c|}
\hline \multicolumn{2}{|c|}{ Ø INTRANSITIVE } & \multicolumn{2}{|c|}{$-t$ TRANSITIVE } \\
\hline səả & 'get torn’' & sq̉et & 'tear it' \\
\hline $\mathrm{k}^{\mathrm{w}} \partial 1$ & ‘spill’ & $\mathrm{k}^{\mathrm{w}}$ ket & 'pour it' \\
\hline $\mathrm{k}^{\mathrm{w}} \partial \mathrm{s}$ & 'burn', 'get hot' & $\hat{\mathrm{k}}^{\mathrm{w}}$ esat & 'burn it' \\
\hline 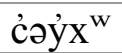 & 'get dry' & cəəy่ ${ }^{w} t$ & ‘dry it’’ \\
\hline ləc̉ & '(container) get full' & ləc̉ət & 'fill it' \\
\hline tàt & 'flipped' & ltet & 'flip it' \\
\hline łəq" & 'get wet' & $\mathrm{kq}^{\mathrm{w}} \partial \mathrm{t}$ & 'wet it' \\
\hline nec̉ & 'be different' & nec̉t & 'change it' \\
\hline${\dot{c} ə \mathfrak{q}^{\mathrm{w}}}^{\mathrm{w}}$ & 'get pierced' & $\dot{c} \dot{q}^{w}$ at & 'pierce it' \\
\hline $\operatorname{cox} \mathrm{x}^{\mathrm{w}}$ & 'increase' & ćn ${ }^{w}$ at & 'add more to it' \\
\hline$\dot{x} \partial x^{w}$ & 'get covered' & $\dot{x} x^{w}$ at & 'cover it' \\
\hline lok $\mathrm{k}^{\mathrm{w}}$ & 'break in two' & $\operatorname{lok}^{\mathrm{w}} \mathrm{at}$ & 'break it in two' \\
\hline $\mathrm{Pak}^{\mathrm{w}}$ & 'get hooked' & Pak ${ }^{\mathrm{w}} \partial \mathrm{t}$ & 'hook it' \\
\hline $\mathrm{tiq}^{\mathrm{w}}$ & 'get hit, bumped' & tiq $\dot{q}^{w} \partial t$ & 'hit, bump it' \\
\hline
\end{tabular}

We see that the Salish data go far beyond the English melt/melt alternation (i.e. the inchoative/causative alternation) to include intransitive verbs that cannot spontaneously occur, but must have an external force (Haspelmath 1993). The robustness of this pattern, along with the distinctly un-English semantics, has led Davis $(1997,2000)$ to take the claim of intransitivity for Salish roots one step further: he posits that all roots are unaccusative. ${ }^{4}$ Under his deep-unaccusativity approach, transitive verbs and unergative verbs are derived in the syntax. The transitive suffix is a $v$ head that brings in an external argument, the agent. Unergative verbs are marked with a variety of suffixes that serve as a $v$ head that both brings in an external argument and cancels the internal argument.

However, what we find in our data is that the claim for universal unaccusativity is not justified. As we show in this paper, there are several types of relationships between the bare root and the alternant with $-t$. Furthermore, when we use tests for establishing unaccusativity as laid out in Gerdts (1991) and Gerdts \& Hukari (2001, 2006), we find surprisingly that only 54 out of 489 roots (11\%) straightforwardly test to be unaccusative, divided into three semantic types as follows: ${ }^{5}$

\section{STATE/TRANSITIVE}

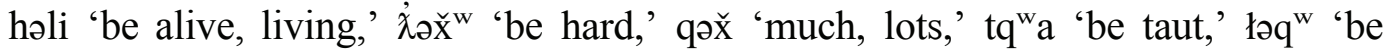

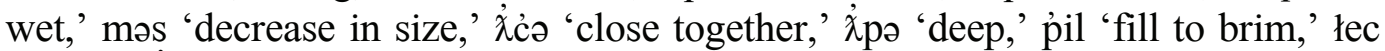
'dark,' təl’ 'flatten, flop'

\footnotetext{
${ }^{4}$ See Davis and Demirdache (2000) for a more refined version of this hypothesis. There verb roots are taken to be semantically "causative" but syntactically unaccusative. Our objections to positing that all roots are of one type are equally applicable to this revised hypothesis.

${ }^{5}$ These tests include the lack of a causative, a desiderative, and a limited control reflexive with an agentive reading.
} 
Donna B. Gerdts and Thomas E. Hukari

PROCESS (SPONTANEOUS)/TRANSITIVE

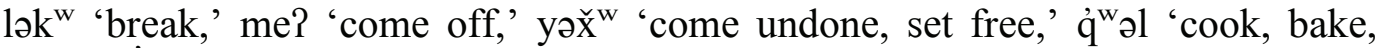
ripen,' $\mathrm{k}^{\mathrm{w}}$ es 'get burnt, scald, injure by a burn,' mq̉ə 'get full of food,' x̌əł 'get hurt,' q̇is 'get knotted,' q̉ay 'get sick, die,' liqw 'get slack,' ċə่ 'get surprised,' sq̉e 'tear,' ć 'qwa 'absorb,' lom 'fold, hem,' łəlq 'soak, flood, (river) rise,' ł'̀ ${ }^{w} a$

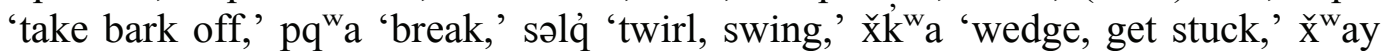
'die (plural),' sik ${ }^{\mathrm{w}}$ 'peel,' ca? 'pull off a layer of clothing,' tłə 'spread, open,' tx ${ }^{\mathrm{w}} \mathrm{a}$ 'uncover,' cən' 'lean against something,' $\mathrm{x}^{\mathrm{w}} \mathrm{iq}$ 'cheer up'

\section{EXTERNALLY CAUSED EVENT/TRANSITIVE}

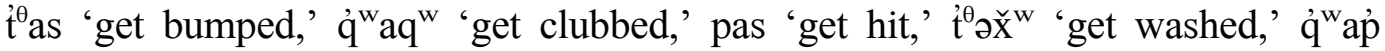
'wrinkle, pleat,' qə’’ 'stick something to something,' $\check{\mathrm{x}}^{\mathrm{w}} \mathrm{q}^{\mathrm{q}}{ }^{\mathrm{w}}$ 'loop,' qit 'tie in the middle,' ' $a q^{\mathrm{w}}$ 'soak up, absorb,' ?aq ${ }^{\mathrm{w}}$ 'brush,' $\mathrm{t}^{\theta} \mathrm{e} \mathrm{k}^{\mathrm{w}}$ 'shine a light on,' pah 'blow on, blow out, inflate it,' qem 'bend,' $t^{\theta}$ is 'nail,' le? 'put away,' pšə 'spit medicine,'

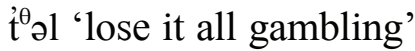

The roots that test to be unaccusative (54) outnumber the roots that straightforwardly test to be unergative (33). The unergative roots split into two types, canonical unergatives, which do not form transitives with the suffix $-t$, and a small group of motion verbs, which do form transitives with $-t:^{6}$

\section{CANONICAL UNERGATIVES}

cam 'go uphill,' hek ${ }^{\mathrm{w}}$ 'recall to mind,' həye? 'depart,' $\mathrm{k}^{\mathrm{w}} \mathrm{i}$ ? 'climb,' łak ${ }^{\mathrm{w}}$ 'fly,' nem 'go,' qłan 'be forward,' q⿳al 'speak,' tax ${ }^{\mathrm{w}}$ 'bring down,' tak ${ }^{\mathrm{w}}$ 'go home,' $\theta$ t 'say to,' x̌in 'growl,' '̌x ${ }^{w}$ te? 'go/come to,' yays 'work,' Pomət 'sit down/rise out of bed,' ?ənəx ${ }^{w}$ 'stop,' ?a:ł 'get on vehicle,' ?eli 'away, take away,' ?ewə 'come here,' ?itət 'sleep,' ta:1 'go to middle of floor,' $\dot{x} \mathrm{iw}$ 'sneak off, run away,' he:w่ 'go away for a long time,' $\mathrm{k}^{\mathrm{w}}$ ayək ${ }^{\mathrm{w}}$ 'fish with line, gaff,' łəne 'go along a way,' təy 'pull (race) a canoe,' łew' 'flee,' tel 'be like'

\section{MOTION VERBS}

łe:1 'go ashore; beach it,' $\mathrm{k}^{\mathrm{w}} \mathrm{e}: 1$ 'hide,' ?əð்q 'go out, get out,' səl’c 'go around, surround,' ' ${ }^{\mathrm{w}} \mathrm{im}$ 'disembark'

However, we did not find an overwhelming preponderance of unaccusative roots that we would expect under the deep unaccusativity hypothesis.

Furthermore, our research has revealed that half of the roots that have alternants with $-t$ are "swingers." That is, the bare root appears in either an unergative or an unaccusative frame, as required by the context. For example, the roots $\dot{p} e^{i} \theta$ 'sew' and $\dot{p} \boldsymbol{\circ} k^{w}$ 'float' behave unergatively with a human (or sentient) subject, denoting an action under the control of the agent NP (see (3) and (5)), but

\footnotetext{
${ }^{6}$ Some of these verbs take $-\check{s}$ as a morphophonemic variant of $-t$.
} 


\section{Salish Intransitive/Transitive Alternations}

they behave unaccusatively with inanimate objects, denoting an activity that the NP undergoes (see (4) and (6)).

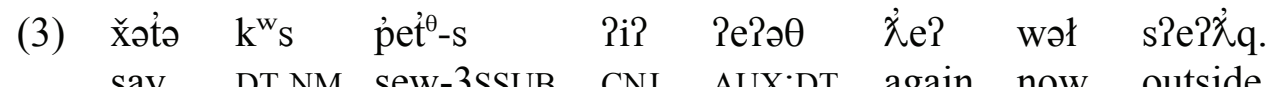
say DT.NM sew-3SSUB CNJ AUX:DT again now outside 'She said she was going to sew and now she's outside.'

(4) ni? pet ${ }^{\theta} \quad \mathrm{k}^{\mathrm{w}} \theta \partial$ qtewəstəns.

AUX sew DT waistband

'The waistband got accidentally sewn together.'

(5)

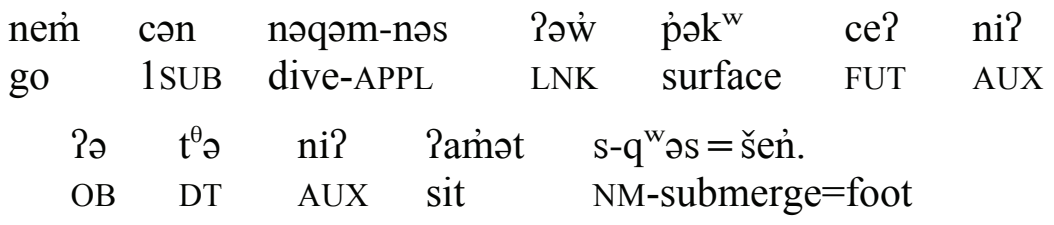

'I'm going to dive, and then I'll come out in front of the one that's got his leg in the water.'

(6) naiət wəł pək $^{\mathrm{w}} \quad \mathrm{t}^{\theta} \partial \quad \mathrm{q}^{\mathrm{w}}$ łeỷ. AUX:DT now surface DT log 'The log has floated up.'

This fact is not unexpected; work on unaccusativity cross-linguistically has shown that verbs in many languages easily switch from one type to another or that types have mixed properties (Levin \& Rappaport Hovav 1995).

Given that global unaccusativity fails to be a semantically interesting hypothesis for Salish languages, we are led back to the question of whether positing intransitivity for all roots is at all insightful.

\section{Transitive Roots}

The first problem that arises for the intransitive root hypothesis is that not all verbs that occur with the $-t$ suffix have a corresponding bare root alternate that can appear as a free-standing word. We find 93 of the 489 roots (19\%) are like this. The following verbs are typical of this type:

ACTIVITIES INVOLVING MANIPULATING, MOVING, ACQUIRING, INGESTING, ETC. $\checkmark$ ha? $\mathrm{x}^{\mathrm{w}}$ 'steam bathe,' Vhes 'ritual brushing,' $\sqrt{\mathrm{k}}{ }^{\mathrm{w}} \mathrm{ey}$ 'bathe in cold water,' $\sqrt{ } \mathrm{y} \mathrm{k}^{\mathrm{w}}$

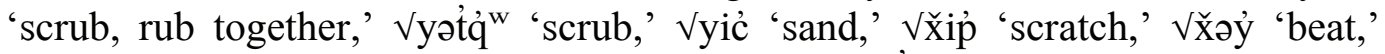
Vtəyq 'move,' Vqix̌ 'slide,' Vyiq 'fell, tip over,' Vq䒕a; 'drop off,' Vhik ' 'rock,' $\sqrt{ }$ cəm 'pack on one's back,' $\sqrt{ }$ Rit 'pack by the handle,' $\sqrt{ }$ še? 'put on lap,' $\backslash$ łaq ${ }^{\text {W }}$ 'tap, pat,' $\sqrt{ } \mathrm{k}^{\mathrm{w}} \mathrm{e}$ ? 'drop it, let go, leave it alone,' $\sqrt{\tan }$ 'leave behind,' $\sqrt{\mathrm{x} i \mathrm{~m}}$ 'grab,' $\sqrt{\grave{\lambda}} \mathrm{k}^{\mathrm{w} a}$ 'grab and pull,' $\sqrt{ } \mathrm{m}^{\mathrm{k}}{ }^{\mathrm{w}}$ 'pick up off the ground,' ${ }$ wen 'throw,' 
Donna B. Gerdts and Thomas E. Hukari

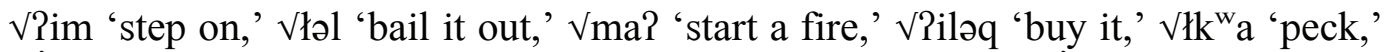

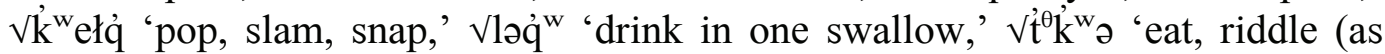
pests do)'

VERBS OF COGNITIVE AND SOCIAL INTERACTION

ฟłeq 'whisper,' $\vee^{\mathrm{k}}$ ełà 'pop, slam, snap,' Vlem 'look at,' Vyən 'laugh at,' V'tqə

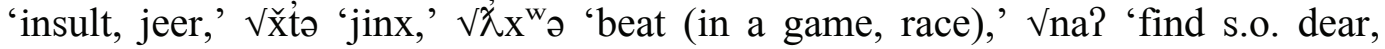
miss,' Vnan 'take someone's side, defend,' $V \mathrm{p} \mathrm{x}^{\mathrm{w}} \mathrm{a}$ 'keep quiet, calm down,' $V$ neh 'name someone,' V'tih 'ask him/her, beg,' VRa: 'call for, invite,' Vya: 'order,' Vcse 'tell (to do),' $\mathfrak{k}^{\mathrm{w}}$ əye 'forbid,' $\sqrt{ } \mathrm{ex}^{\mathrm{w}} \mathrm{e}$ ? 'give, share with'

These verbs have semantics typical of transitive verbs cross-linguistically, e.g., activity verbs involving a direct effect on the patient, often with an instrument; verbs involving the agent moving the patient; ditransitive verbs of giving, letting, and telling, etc. In fact, the simplest analysis to posit for these verbs is that the roots are transitive.

Such verbs show us two things. First, that some roots are, in fact, basically transitive. Second, that transitive marking, rather than functioning as a means of deriving transitive from intransitive forms, should be viewed as inflection on roots that are already semantically transitive.

\section{Unergative Verbs with Transitive Semantics}

A second problem for the intransitive root hypothesis comes from a class of verb roots that show a $Ø /$ transitive alternation, but not of the expected pattern. The agent rather than the patient is the constant factor across the two constructions. Furthermore, even the intransitive alternate is semantically transitive: the obliquemarked NP is the semantic patient in the intransitive (a) examples corresponding to the direct object in the transitive (b) examples. ${ }^{7}$

a. nem č̀ $\mathrm{k}^{\mathrm{w}} \check{\mathrm{x}} \quad$ Pə $\quad \mathrm{k}^{\mathrm{w}} \theta \partial \quad$ sce:łtən!

go fry OB DT salmon

'Go fry some salmon!'

b. nəwə-s nem č̉ว $\mathrm{k}^{\mathrm{w}} \check{\mathrm{x}}-\mathrm{t} \quad \mathrm{t}^{\theta} \partial$ səplil! you-NM go fry-TR DT bread

'You go fry the bread!'
a. nem łə tə⿳่ šəyq

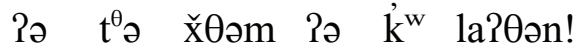 go EMPH bit look.through OB DT box OB DT plate 'Go look through the box for a plate!'

\footnotetext{
${ }^{7}$ More precisely, this is a particular kind of oblique-marked NP that we refer to as an oblique object (Gerdts 1988a, Gerdts \& Hukari 1998).
} 


\section{Salish Intransitive/Transitive Alternations}

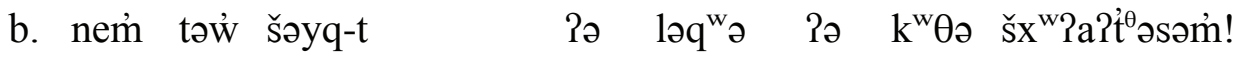
go bit look.through-TR DT suitcase OB DT towel

'Go look through the suitcase for a towel!'
a.

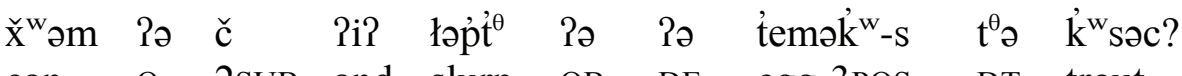

can $Q$ 2SUB and slurp $\mathrm{OB} \quad \mathrm{D}$

'Can you slurp up the trout eggs?'

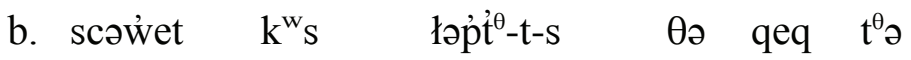
know.how DT.NM slup-TR-3POS DT baby DT

ščyəmən-åł nutəls.

Chinese-ATTRIB noodles

'The baby knows how to slurp up the Chinese noodles.'

This is a significant class of verbs: 35 of the 489 verb roots (7\%) exhibit this pattern. They are as follows:

SEMANTICALLY TRANSITIVE WITH OBLIQUE OBJECT

liš 'bite and tear it apart,' q"əl’ 'boil,' səw่q 'seek,' Peməq 'return, give back,'

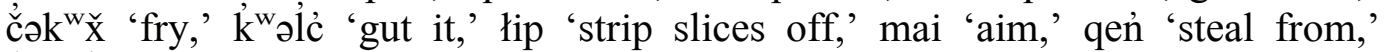
خेəmk ${ }^{\mathrm{w}}$ 'pop in mouth,' šəyq 'ransack, go through looking,' tel 'half-drying fish,' $\mathrm{x}^{\mathrm{w}} \mathrm{ik}^{\mathrm{w}}$ 'brush close by,' $\mathrm{x}^{\mathrm{i}} \mathrm{k}^{\mathrm{w}}$ 'gnaw,' $\mathrm{x}^{\mathrm{t}} \mathrm{k}^{\mathrm{w}}{ }^{\mathrm{w}}$ 'carve,' qeləc் 'spin (wool, etc.),'

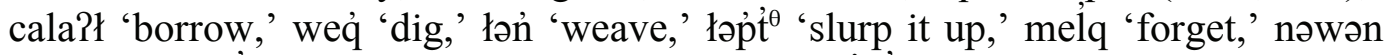
'will it to,' '̇ee?ə 'propose,' $\mathrm{k}^{\mathrm{w}} \mathrm{uk}^{\mathrm{w}}$ 'cook it,' x̌tek ${ }^{\mathrm{w}}$ 'carve,' łən் 'weave,' has 'blow on it,' łrt ' 'joke with someone,' qama? 'nurse,' sem 'sell,' tem 'guess,'

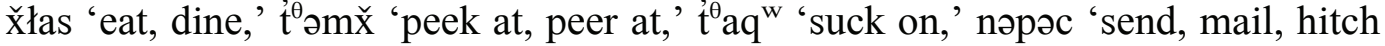
ride'

Like the verb roots in the previous section, these verbs denote semantically purposeful actions, often activities that require some duration. We have no explanation for why these verbs appear in the oblique object construction while the verbs in the previous section do not. Nevertheless, both groups of verbs seem to denote transitive events.

\section{Bare Root is Unaccusative but Semantically Transitive}

A third problem for the intransitive root hypothesis comes from a class of verbs that might at first seem like classic unaccusatives, since they appear in intransitive clauses where the sole argument is the patient. The following are typical examples: 
Donna B. Gerdts and Thomas E. Hukari

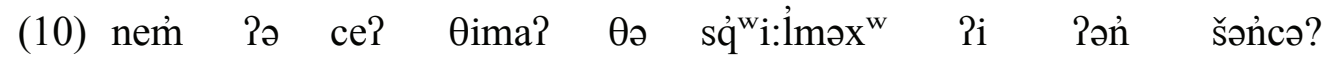
go Q FUT freeze DT blackberry AUX 2POS pick 'Are you going to freeze the blackberries you picked?'

[Lit: 'Are the blackberries that you picked going to go freeze?']

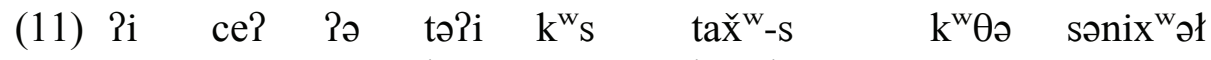
AUX FUT OB here DT.NM beach-3POS DT canoes

ใə⿳่ $\mathrm{k}^{\mathrm{w}}$ eyələs.

LNK tomorrow

'You will beach the canoes over here tomorrow.'

[Lit: 'The canoes will be beached here tomorrow.']

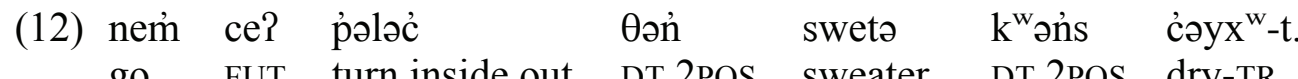
go FUT turn.inside.out DT.2POS sweater DT.2POS dry-TR. 'You will turn your sweater inside out to dry.' [Lit: 'Your sweater will be turned inside out when you dry it.']
(13) ?əỷ $\mathrm{k}^{\mathrm{w}} \mathrm{s}$ qiq̀-s $\mathrm{t}^{\theta} ə$ qeq good DT-NM bind-3POS DT baby not EMPH and stop.cry 'You'd better bind the baby that hasn't stopped crying.' [Lit: 'It's good for the baby that hasn't stopped crying to be bound.']

However, this construction is highly marked semantically. That is, while the transitive alternants of these verbs are easily used in a variety of contexts, the intransitive verbs are used only in a construction that we call the pseudo-transitive imperative. It functions as a polite or indirect imperative. As seen in the English translation that speakers give for such examples, the agent is implied. It is usually translated as second person singular or plural, but occasionally a first person hortative. The sentence is usually framed in the future (10)-(12), as a question (10), or with the higher predicate $2 \partial y^{\prime}$ 'good' (13). Furthermore, the construction allows the motion auxiliary nem 'go,' which is otherwise limited to clauses where there is an agent that can move (Gerdts 1988b). ${ }^{8}$ For example, in (10) and (12) above, it is the implied second person agent that is thought to be moving.

We were actually surprised to find that a fair number of verbs roots (38 out of 489 or $8 \%$ ) appear in the pseudo-transitive imperative construction:

PSEUDO-TRANSITIVE IMPERATIVES

$\mathrm{k}^{\mathrm{w}} \mathrm{c}$ 'shout at, use a sharp tone with,' $\mathrm{k}^{\mathrm{w}} \theta$ ə 'lie down (a quadruped), crouch,'

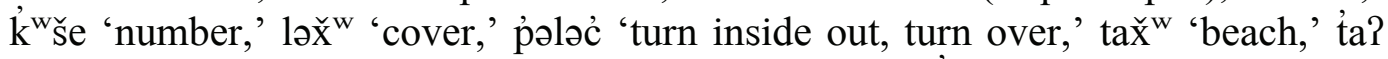

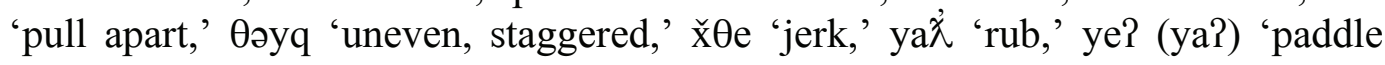

\footnotetext{
${ }^{8}$ There is one exception to this condition on animacy: the subject of verbs expressing natural events such as the tide going out or the moon setting can take motion auxiliaries.
} 


\section{Salish Intransitive/Transitive Alternations}

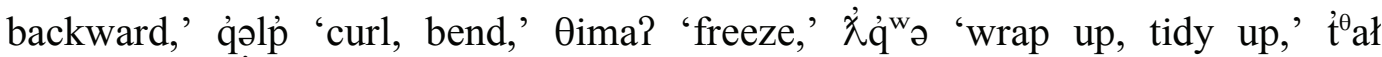
'dampen,' $\mathrm{x}^{\mathrm{w}} \mathrm{k}^{\mathrm{w}} \mathrm{a}$ 'pull, pull the slack up,' Piye?q 'change,' łte 'flip,' pe? 'skim cream off milk, flatten,' qәye? 'take out,' ?aləx̌ 'collect,' ’̀ əрх̌ 'scatter it, spread it, broadcast,' '̇y $\mathrm{y}^{\theta}$ 'bring together,' ' ${ }^{\mathrm{w}}$ ay 'scrape, singe a canoe,' sat 'suck,' səỳt 'tickle him/her,' šak ${ }^{\mathrm{w}}$ 'bathe,' šem 'dry, smoke,' taləx̆ ${ }^{\mathrm{w}}$ 'send away, chase away,' wet ${ }^{\dagger}$ 'knit; pry with a tool,' x̌cə 'figure out,' ćx ${ }^{\mathrm{w}} \mathrm{a}$ 'more, add more to it,'

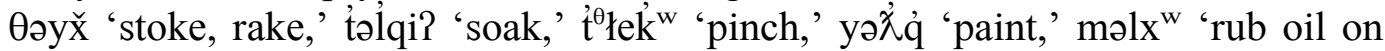
it, grease it'

In many cases, the English equivalents are transitive verbs, though in some cases there are also unaccusative counterparts in English. Again, we have no explanation for why these verb roots differ from the roots in the previous two sections. However, the best analysis for them is that these roots are basically transitive rather than unaccusative in Halkomelem, since the transitive alternants are semantically neutral.

\section{Conclusion}

In sum, roots that take the transitive suffix fall into two types: those where the bare root can easily appear in an unaccusative frame and those that cannot. Typical unaccusative verbs denote processes, with or without an implied external force, and also a handful of states. Those that are not easily classified as unaccusative include a small group of motion verbs, bare roots that appear in an unaccusative frame only in a pseudo-transitive imperative, bare roots that appear in an unergative frame with an oblique-marked object, or those that cannot appear as bare roots at all. These roots are probably best analyzed as being semantically transitive, as the transitive rather than the intransitive alternant (if there is one) seems to be more basic. We summarize our results in Table 2:

Table 2: The semantics of roots taking the transitive suffix

\begin{tabular}{|r|c|c|c|}
\hline & UNACCUSATIVE & UNERGATIVE & TRANSITIVE \\
\hline STATE & 12 & - & - \\
\hline SPONTANEOUS PROCESS & 26 & - & - \\
\hline EXTERNAL FORCE & 38 & - & - \\
\hline MOTION VERBS & - & 5 & - \\
\hline PSEUDO-TRANSITIVE & - & - & 38 \\
\hline $\begin{array}{r}\text { UNERGATIVE WITH } \\
\text { OBLIQUE OBJECT }\end{array}$ & - & - & 35 \\
\hline TRANSITIVE & - & - & 47 \\
\hline TOTAL & 76 & 5 & 121 \\
\hline
\end{tabular}

This table gives information on 201 of the 407 roots that allow $-t$. The other 206 roots are "swingers," exhibiting mixed properties, as discussed in the introduction. Leaving the indeterminate ones aside, we can still say that any 
Donna B. Gerdts and Thomas E. Hukari

hypothesis that tries to put all the roots into a single class is uninsightful for the Halkomelem data. At least some of the roots are transitive, and, as discussed in Section 1, some appear to be unergative.

In other words, Halkomelem probably exhibits the normal tripartite system: there are three major verb classes - unaccusative, unergative, and transitive - and these map to three different syntactic structures. ${ }^{9}$ An unaccusative-based syntactic architecture is overly simplistic and provides no insight into the lexical complexities of verb classification in Salish.

Alternatively, we might heed Piñón's (2001a, 2001b) warning against naively taking the morphology at face value. Under his "least common denominator" analysis (cf. Parsons 1990), verb stems are neutral (or alternating) with respect to argument structure. Both transitive and intransitive verbs are built from these neutral verb stems, rather than one being derived from the other. Moreover, the derivation is lexical and therefore subject to conditions on the semantics of event structure (Levin \& Rappaport Hovav 2005, and references therein). The neutral approach to alternations not only has cross-linguistic appeal, given the variety of morphological marking patterns found within and across languages (Haspelmath 1993), but also makes sense for Salish, where a unidirectional analysis turns out not to be as promising as it might initially appear, as we have discussed herein.

Whether we posit three distinct classes of roots and then sort out which class or classes a particular root belongs to, or we posit neutral roots and then give the rules for building types of verbs from them, we are left with the task of trying to make sense of the semantics of verb classes. This paper is one step in this enterprise.

\section{References}

Davis, Henry. 1997. Deep Unaccusativity and Zero Syntax in St'át'imcets. In Amaya Mendikoetxea and Myriam Uribe-Etxebarria, eds., Theoretical Issues at the Morphology-Syntax Interface, 55-96. Bilbao: Supplements of the International Journal of Basque Linguistics and Philology.

Davis, Henry. 2000. Salish Evidence on the Causative-Inchoative Alternation. In Wolfgang U. Dressler, Oskar E. Pfeiffer, Markus Pöchtrager, and John R. Rennison, eds., Morphological Analysis in Comparison, 25-60. [Current Issues in Linguistic Theory 201.] Amsterdam: John Benjamins.

Davis, Henry, and Hamida Demirdache. 2000. On Lexical Verb Meanings: Evidence from Salish. In Carol Tenny and James Pustejovsky, eds., Events as Grammatical Objects, 97-142. Stanford, CA: CSLI Publications.

Gerdts, Donna B. 1988a. Object and Absolutive in Halkomelem Salish. New York: Garland.

\footnotetext{
${ }^{9}$ See Levin \& Rappaport Hovav (2005) for a survey of how this is accomplished in various theories.
} 


\section{Salish Intransitive/Transitive Alternations}

Gerdts, Donna B. 1988b. Semantic Linking and Relational Structure in Desideratives. Linguistics 26:843-872.

Gerdts, Donna B. 1991. Unaccusative Mismatches in Halkomelem Salish. International Journal of American Linguistics 57:230-250.

Gerdts, Donna B., and Thomas E. Hukari. 1998. Inside and Outside the Middle. Papers for the 33rd International Conference on Salish and Neighboring Languages, Seattle, Washington, 166-220.

Gerdts, Donna B., and Thomas E. Hukari. 2001. The Dual Structure of Halkomelem Motion Verbs. Proceedings of WAIL 2000, Santa Barbara Working Papers in Linguistics, Vol. 10, 33-46.

Gerdts, Donna B., and Thomas E. Hukari. 2006. From Agent-oriented Modality to Aspect in Halkomelem. Paper presented at SSILA, Albuquerque, New Mexico.

Haspelmath, Martin. 1993. More on the Typology of Inchoative/Causative Verb Alternations. In Bernard Comrie and Maria Polinsky, eds., Causatives and Transitivity, 87-120. Amsterdam: John Benjamins.

Hess, Thomas M. 1973. Agent in a Coast Salish Language. International Journal of American Linguistics 29:89-97.

Jelinek, Eloise. 1994. Transitivity and Voice in Lummi. Papers for the $29^{\text {th }}$ International Conference on Salish and Neighboring Languages, Pablo, Montana.

Kuipers, Aert H. 1968. The Categories Verb-Noun and Transitive-Intransitive in English and Squamish. Lingua 21:620-626.

Levin, Beth, and Malka Rappaport Hovav. 1995. Unaccusativity: At the SyntaxLexical Semantics Interface. Cambridge, MA: MIT Press.

Levin, Beth, and Malka Rappaport Hovav. 2005. Argument Realization. Cambridge, UK: Cambridge University Press.

Nater, Hank F. 1984. The Bella Coola Language. [Mercury Series, Ethnology Service Papers 92.] Ottawa: National Museum of Man.

Nichols, Johanna, David A. Peterson, and Jonathan Barnes. 2004. Transitivizing and Detransitivizing Languages. Language Typology 8:149-211.

Parsons, Terence. 1990. Events in the Semantics of English: A Study in Subatomic Semantics. Cambridge, MA: MIT Press.

Piñón, Christopher. 2001a. A Finer Look at the Causative-Inchoative Alternation. In Rachel Hastings, Brendan Jackson, and Zsofia Zvolenszky, eds., Proceedings of Semantics and Linguistic Theory 11. Ithaca, NY: CLC Publications, Cornell University.

Piñón, Christopher. 2001b. Modelling the Causative-Inchoative Alternation. Linguistische Arbeitsberichte 76:273-293. University of Leipzig.

Suttles, Wayne. 2004. Musqueam Reference Grammar. Vancouver: UBC Press.

Thomason, Sarah, and Daniel Everett. 1993. Transitivity in Flathead. Papers for the 28th International Conference on Salish and Neighboring Languages, Seattle, Washington, 317-344. 
Donna B. Gerdts and Thomas E. Hukari

\author{
Donna B. Gerdts \\ Department of Linguistics \\ Simon Fraser University \\ Burnaby, BC V5A 1S6 \\ Canada \\ gerdts@sfu.ca \\ Thomas E. Hukari \\ Department of Linguistics \\ University of Victoria \\ Victoria, BC V8W 3P4 \\ Canada
}

hukari@uvic.ca 